\title{
Profile of forensic psychiatric inpatients referred to the Free State Psychiatric Complex, 2004 - 2008
}

\author{
N Strydom \\ C Pienaar \\ A Dreyer \\ L van der Merwe \\ B Jansen van Rensburg \\ MB ChB students, Faculty of Health Sciences, University \\ of the Free State, Bloemfontein
}

F J W Calitz, BA (Hons), MA (Clin Psych), D Phil

L M van der Merwe, BA (Hons), MA (Clin Psych), D Phil

Department of Psychiatry, Faculty of Health Sciences,

University of the Free State

G Joubert, BA, MSC

Department of Biostatistics, Faculty of Health Sciences, University of the Free State

Introduction. An accused found unfit to stand trial and/or not criminally responsible for his/her actions because of mental illness, is declared a state patient by the court.

Aim. The aim of the study was to analyse the biographical data and relevant particulars of forensic psychiatric inpatients who were admitted to the Free State Psychiatric Complex (FSPC) according to section 42 of the Mental Health Care Act (No. 17 of 2002), from 2004 to 2008.

Study design. A descriptive, retrospective study was conducted.

Method. One hundred and twenty forensic psychiatric inpatients admitted to the FSCP in terms of section 42 of the Mental Health Care Act during the period 2004 - 2008 were included in the study.

Results. The majority of the offenders were male (95.8\%), unmarried (83.8\%) and unemployed (81.5\%). The median age was 32.5 years. Most of the offences against persons were of a sexual nature $(45.8 \%)$. The main offence against property was vandalism (40.6\%). Most of the patients in the study had a history of abusing substances such as alcohol $(74 \%)$, cannabis $(66.7 \%)$, tobacco $(29.6 \%)$ and glue (6.2\%). More than half $(55.5 \%)$ of the forensic inpatients were diagnosed with schizophrenia, followed by mental retardation (10\%) and bipolar mood disorder (9.2\%). Fiftyeight per cent of the participants had received treatment for a mental illness prior to the crime, and $63 \%$ were also known to have poor compliance and to have defaulted from treatment in the past. Eighty per cent of the participants reported having family or friends willing to accommodate them upon discharge.

Conclusion. The majority of the crimes committed were against persons, with rape being the most common. Most of the participants were diagnosed with schizophrenia. The following factors that may influence the rehabilitation, management and training programmes for state patients were identified: active symptoms of a major mental illness such as schizophrenia, current substance abuse, a history of substance abuse, seriousness of the crime committed, medication compliance, a psychiatric history, and family or friends willing to accommodate the participant upon discharge.

South African criminal law on mental illness came to pass as a consequence of the acquittal of Demitrios Tsafendas, who assassinated the then Prime Minister, Hendrik Verwoerd, in 1966. A commission of inquiry into 'the Responsibility of Mentally Deranged Persons' was constituted in 1966 and chaired by Judge Frans Rumpff. The Commission conducted an extensive investigation into mental illness and considered the evidence of a vast number of psychologists, psychiatrists and lawyers. As a result of the Commission's recommendations, the legislature enacted the requirements for the defence of mental illness along with a number of procedural matters.

All these provisions are contained in Chapter 13 of the Criminal Procedure Act No. 51 of 1977 and consist of three sections. Section 77 addresses the defendant's ability to understand the judicial proceedings, while section 78 discusses the mental state of the accused at the time of committing the crime. Section 79 deals with the procedures for psychiatric assessments of accused persons. ${ }^{2,3}$ An accused found unfit to stand trial or not responsible for his/her actions because of mental illness, is declared a state patient by the court. Section 42 of the Mental Health Care Act (Act No. 17 of 2002) deals with state patients.

Several overseas studies were done on forensic patients who were found not criminally responsible and not competent to stand trial. Douglas et al. ${ }^{5}$ found in their study of 100 forensic psychiatric patients that most of the participants were male, 
did not have children and were unmarried. The majority of the patients were unemployed, and less than half had completed high school. Most had previously been charged with violent behaviour, 48 had a previous violence conviction, the majority had a current violent index offence, and 34 had a juvenile criminal record. The majority had previously received psychiatric treatment, including inpatient treatment. Primary diagnoses were schizophrenia followed by mood disorders and substance-related disorders. A quarter of the sample had a diagnosis of personality disorder. ${ }^{5}$

A study conducted by Wennberg and Daderman ${ }^{6}$ in Sweden found that alcohol-related problems in males were two to three times more common in the forensic psychiatric sample than in the general population. Twenty-five per cent of the forensic psychiatric patients had a diagnosis of alcohol dependency or abuse. ${ }^{\circ}$

Skipworth et al.? examined the clinical and forensic outcomes of defendants found not guilty because of insanity in New Zealand. The participants (135) were predominantly male (83\%). The primary diagnosis was schizophrenia (59\%); an additional 17\% had other psychotic disorders. Mood disorders accounted for $13 \%$, organic disorders for $3 \%$ and personality disorders for $8 \%$ of the cases. The majority were diagnosed with brief psychotic episodes at the time of the crime. Murder was the main offence, followed by sexual violence. Property offences represented $9.6 \%$ of the crimes. Offenders with more serious offences were securely detained for longer periods, on average 6 years in the case of those charged with murder. Most patients were re-admitted over the decade following discharge. Only $6 \%$ had violently re-offended 2 years after release into the community.

Wang et al. ${ }^{8}$ re-assessed the aftercare treatment of 240 mentally ill offenders found not guilty due to a mental disability in Hunan, China. The majority of the patients (87.7\%) were male, more than half had a middle-school level of education, and most were unmarried. About $69 \%$ of the study population came from rural areas. The proportions of patients who had a psychiatric and conviction history before the index offence were $88.8 \%$ and $17.1 \%$, respectively, of whom most had been convicted of a violent crime. These crimes included murder or attempted murder $(57.1 \%)$, assault $(12.9 \%)$, robbery $(8.2 \%)$ and sexual assault (7. $1 \%)$. A total of $71.8 \%$ of the patients were diagnosed with schizophrenia, followed by mood disorder (12.4\%) and mental retardation (7.6\%). Most (64.1\%) of the mentally ill offenders were found not criminally responsible and $15.9 \%$ had diminished criminal responsibility, while the remaining $20 \%$ were found to be fully criminally responsible.

In South Africa, Barrett et al. ${ }^{9}$ found that the majority of crimes were committed against persons, with rape being the most common. With regard to psychiatric diagnoses, their study revealed that schizophrenia was the most common diagnosis. The majority of the participants were considered to be both unfit to stand trial and not criminally responsible. More than half of the participants (58\%) received psychiatric medication. The drug most commonly prescribed was haloperidol. ${ }^{9}$
One of the most important issues to be considered in dealing with state patients is evaluating potential risk to the community; i.e. if they pose a danger to others. ${ }^{10}$ Chaimowitz et al." divided risk factors posed by mentally abnormal offenders into modifiable (dynamic) and non-modifiable (static) factors. Modifiable factors include active symptoms of major mental illness, substance abuse, medication adherence, insight into illnesses/disorders, anger management and involvement with criminal associates. Non-modifiable factors include criminal history, presence of certain personality disorders (especially antisocial personality disorder), history of substance abuse, low intelligence and cognitive disorders, including acquired injury, developmental delay and dementias. Yates et al. ${ }^{12}$ are of the opinion that medical compliance is the one most enduring factor associated with clinical stability and prevention of criminal behaviour.

Relatively few research projects regarding mentally ill offenders have been undertaken, especially in South Africa. We therefore recognised the need for an in-depth study to investigate sociodemographic characteristics of state patients, summarise the findings regarding criminal responsibility and competence to stand trial, and identify the most common psychiatric conditions associated with these crimes, and factors that may influence rehabilitation, management and training programmes for state patients.

\section{Aim of the study}

The aim of the study was to describe the profile of forensic psychiatric patients admitted to the Free State Psychiatric Complex (FSPC) in Bloemfontein according to section 42 of the Mental Health Care Act, from 2004 to 2008.

\section{Methods}

A descriptive, retrospective study was conducted. One hundred and twenty forensic psychiatric inpatients admitted to the FSPC in terms of section 42 of the Mental Health Care Act from 2004 to 2008 were included in the study.

A data capturing sheet was compiled and used to record information from the patients' clinical files that provided a basic demographic profile for them, and included socio-demographic data, observational findings, diagnoses and offences. A pilot study on 10 files of state patients preceded the main study.

The research protocol was approved by the Ethics Committee of the Faculty of Health Sciences, University of the Free State (UFS). Permission to access the patient files was obtained from the Chief Executive Officer of the FSPC.

Data analysis was performed by the Department of Biostatistics, UFS. Results were summarised as frequencies and percentages in the case of categorical variables, and means or percentiles for numerical variables. 


\section{Results and discussion Demographic information}

The socio-demographic details of the study patients are summarised in Table I. One hundred and twenty forensic psychiatric inpatients were included, of whom $95.8 \%$ were male. Their mean age was 32.5 years (range 14 - 66 years).

Ninety participants (75\%) were Sotho-speaking. Most (81.5\%) were unemployed and dependent on a government disability grant. This large proportion of unemployed participants is understandable, since schizophrenia was the most common diagnosis in the study population, and it is well known that this diagnosis is associated with high rates of unemployment

\begin{tabular}{|c|c|}
\hline Characteristics & $\begin{array}{l}\% \text { of } \\
\text { participants } \\
(N=120)\end{array}$ \\
\hline $\begin{array}{l}\text { Gender } \\
\text { Male } \\
\text { Female }\end{array}$ & $\begin{array}{l}95.8 \\
4.2\end{array}$ \\
\hline $\begin{array}{l}\text { Language } \\
\text { Sesotho } \\
\text { Afrikaans } \\
\text { isiXhosa } \\
\text { isizulu } \\
\text { Setswana } \\
\text { English }\end{array}$ & $\begin{array}{l}75.0 \\
10.8 \\
5.0 \\
4.2 \\
4.2 \\
0.8\end{array}$ \\
\hline $\begin{array}{l}\text { Marital status } \\
\text { Unmarried } \\
\text { Married } \\
\text { Divorced } \\
\text { Widow/er }\end{array}$ & $\begin{array}{l}83.8 \\
7.2 \\
6.3 \\
2.7\end{array}$ \\
\hline $\begin{array}{l}\text { Employment sta } \\
\text { Unemployed } \\
\text { Employed }\end{array}$ & $\begin{array}{l}81.5 \\
5.9\end{array}$ \\
\hline $\begin{array}{l}\text { Substance abus } \\
\text { Alcohol } \\
\text { Cannabis } \\
\text { Tobacco } \\
\text { Glue }\end{array}$ & $\begin{array}{l}74.0 \\
66.7 \\
29.6 \\
6.2\end{array}$ \\
\hline $\begin{array}{l}\text { Family/friends w } \\
\text { accommodate } \\
\text { discharge }\end{array}$ & \\
\hline $\begin{array}{l}\text { Yes } \\
\text { No }\end{array}$ & $\begin{array}{l}80.0 \\
20.0\end{array}$ \\
\hline
\end{tabular}

Table II. Offences committed against persons

$\begin{array}{lc}\text { Offence } & \begin{array}{c}\text { \% of participants } \\ (\mathbf{N = 1 2 0 )}\end{array} \\ \text { Rape } & 35.4 \\ \text { Assault } & 34.4 \\ \text { Murder } & 19.8 \\ \text { Attempted rape } & 7.3 \\ \text { Sexual offences other than rape } & 3.1 \\ \end{array}$

More than $80 \%$ of the participants were not married. This finding can partly be explained by the fact that the average age at which South Africans marry is 30 years. Another explanation could be that most participants were diagnosed with schizophrenia, and their illness might have disrupted their personal, social, emotional and mental development, leading to social withdrawal."

Most patients in our study had a history of substance abuse (Table I). This finding was similar to that of Mosotho et al., ${ }^{14}$ that alcohol was the most commonly abused substance in Mangaung (Bloemfontein), followed by nicotine and cannabis. It does, however, contrast with results from other South African studies where the prevalence of hard drugs such as heroin, cocaine, ecstasy and Mandrax was much higher.

Eighty per cent of the participants reported having family or friends willing to accommodate them on discharge. This is a surprising finding, as lack of family support is one of the main reasons why state patients cannot be discharged.

\section{Offences committed}

Most ( $N=96,80 \%$ ) of the offences committed were against persons (Table II). Sexual offences dominated, with 35.4\% patients accused of rape. In total, sexual offences comprised $45.8 \%$ of all offences against persons.

In our study, the most common crime against property (Table III) was vandalism (40.6\%). Only $6.7 \%$ of the 120 patients committed crimes against both property and a person.

\begin{tabular}{lc} 
Table III. Offences committed against property \\
\hline Offence & \% of participants $(\mathbf{N = 1 2 0})$ \\
Vandalism & 40.6 \\
Theft & 21.9 \\
Burglary & 12.5 \\
Robbery & 9.4 \\
Arson & 3.1 \\
\end{tabular}

Table IV. Psychiatric diagnoses of participants

$\begin{array}{lr}\text { Diagnosis } & (\mathrm{N}=12 \\ \text { Schizophrenia } & 55.5 \\ \text { Mental retardation } & 10.0 \\ \text { Bipolar mood disorder } & 9.2 \\ \text { Psychosis due to a general } & 5.9 \\ \text { medical condition } & 4.2 \\ \text { Psychosis due to epilepsy } & 3.4 \\ \text { Psychosis due to substance } & 1.7 \\ \text { abuse } & 10.0 \\ \text { Delirium } & \\ \text { Other } & \end{array}$




\section{Psychiatric diagnoses}

The psychiatric diagnoses of participants are shown in Table IV. Most (55.5\%) participants were diagnosed with schizophrenia.

The reporting psychiatrist(s) and the multi-professional team responsible for the 30-day psychiatric observation, according to sections 77, 78 and 79 of the Criminal Procedure Act, found the majority ( $N=96,80 \%)$ of participants not able to stand trial and not criminally responsible. Charges against $19(17.3 \%)$ of the offenders were withdrawn, with the understanding that the hospital would undertake further management of these participants. Only $2(1.8 \%)$ were found competent to stand trial and not criminally responsible, and 1 (0.9\%) was found criminally responsible and not competent to stand trial.

The high incidence $(58 \%)$ of participants who received treatment for a mental illness prior to the crime and who were also noncompliant (63\%) and defaulted from treatment is cause for concern. Their crimes might have been forestalled by adequate treatment and monitoring of compliance.

\section{Factors that may influence rehabilitation, management and training programmes for forensic patients}

Careful consideration should be given to the following factors that may influence the treatment of state patients: active symptoms of a major mental illness such as schizophrenia, current substance abuse, a history of substance abuse, severity of the crime committed, medication compliance, psychiatric history, and availability of family or friends willing to accommodate the patient upon discharge.

Poor insight in state patients, for example those diagnosed with schizophrenia, may have a negative impact on their treatment compliance. Yates et al. $^{12}$ are of the opinion that medical compliance is the single most enduring factor associated with clinical stability and prevention of criminal behaviour. According to Chaimowitz et al.," insight as well as treatment adherence are independent contributors to the risk of violence.

Because of the high prevalence of current and previous substance abuse in the study group, substance abuse rehabilitation should also be considered as an essential element of forensic programmes. Lack of family support remains one of the main reasons why state patients are not discharged.

The links between crime, violence and mental illness have been studied and established thoroughly. ${ }^{11,16}$ A well-developed system to monitor all state patients in psychiatric hospitals and those discharged into the community will ensure that patients who relapse are detected and treated before again committing a criminal act.

\section{Conclusion}

The purpose of the study was to determine the socio-demographic, psychiatric and offence profile of state patients referred to the FSPC from 2004 to 2008. The majority of crimes committed by these patients were against persons, with rape being the most common. Most of the participants were diagnosed with schizophrenia.

Although the present study provided noteworthy findings, the results should be interpreted with care, especially as far as their generalisation is concerned. Only state patients at the FSPC, and therefore from its catchment area, were included in the study. A limitation of the study was that some files were incomplete or not completed correctly. Nevertheless, the study contributes substantially to important data regarding demographics, psychiatric diagnoses and offence profiles in a field that has been largely neglected in South Africa.

\section{References}

Press, 2006

2. Snyman CR. Strafreg. 5th ed. Durban: LexisNexis Butterworth, 2006

3. Criminal Procedure Act 51 of 1977

4. Mental Health Care Act No. 17 of 2002

5. Douglas KS, Ogloff JRP, Hart SD. Evaluation of a model of violence risk assessment among forensic psychiatric patients. Psychiatr Serv 2003;54:1372-1379.

6. Wennberg P, Daderman AM. Alcohol-related symptoms in a sample of male forensic psychiatric patients and a normal representative cohort of Swedish males. German J Psychiatry 2000;3:21-26

7. Skipworth J, Brinded P, Chaplow D, Frampton C. Insanity acquittee outcomes in New Zealand. Aust N ZJ Psychiatry 2006;40: 1003-1009

8. Wang $X$, Zhang D, Jiang S, Bai Y, Cucolo HE, Perlin ML. Reassessing the aftercare treatment of individuals found not guilty due to a mental disability in Hunan, China: supplemental study into the disposition of mentally ill offenders after forensic psychiatric assessment. Aust N ZJ Psychiatry 2007;41:337-342.

9. Barrett SP, du Plooy J, du Toit J, Wilmans S, Calitz FJW, Joubert G. Profile of mentally ill offenders referred to the Free State Psychiatric Complex. S Afr J Psychiatry 2007; 13:56-58.

10. Zabow T, Van Rensburg P, Vorster M. Psychiatry and the Law. In: Robertson B, Allwood C, Gagiano CA, eds. Textbook of Psychiatry for South Africa. Cape Town: Oxford University Press, 2001.

11. Chaimowitz GA, Mamak M, Padget R. Management of the mentally abnormal offender. Brief Treat Crisis Interv 2008;8: 15-26.

12. Yates KF, Khunz M, Khan A, Volavka SR. Psychiatric patients with histories of aggression and crime five years after discharge from a cognitive behavioral program. J Forens Psychiatry Psychol 2010;21:167-188.

13. Budlender D, Chobokoane N, Simelane S. Marriage patterns in South Africa: methodological and substantive issues. Southern African Journal of Demography 2004;9: 1-26.

14. Mosotho NL. Clinical manifestations of mental disorders among Sesotho speakers in Mangaung. Unpublished PhD thesis, University of the Free State, Bloemfontein, 2005.

15. Plüddemann A, Parry C, Bhana A, Harker N, Potgieter H, Gerber W. Monitoring alcohol and drug abuse trends in South Africa (July 1996 - December 2004), Phase 16. South African Community Epidemiology Network on Drug Use Research (SACENDU) Research Brief 2004;7: 1-12

16. Sirotic F. Correlates of crime and violence among persons with mental disorder: an evidence-based review. Brief Treat Crisis Interv 2008;8:171-194. 